\title{
Cytarabine/Topotecan Regimen
}

National Cancer Institute

\section{Source}

National Cancer Institute. Cytarabine/Topotecan Regimen. NCI Thesaurus. Code

C10821.

A regimen consisting of cytarabine and topotecan that may be used in certain types of acute myeloid leukemia (AML). 